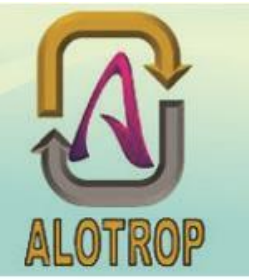

\title{
PENERAPAN MODEL PEMBELAJARAN MENCARI PASANGAN DAN BERTUKAR PASANGAN DALAM KELOMPOK DISKUSI TERHADAP HASIL BELAJAR SISWA PADA MATERI SISTEM KOLOID KELAS XI IPA MAN 1 KOTA BENGKULU
} Sella Aprianika ${ }^{*}$, Amrul Bahar ${ }^{3}$, Salastri Rohiat ${ }^{3}$

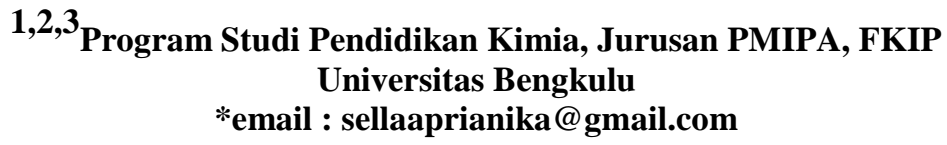

\section{Abstract}

This study aims to determine differences in student learning outcomes using a model of learning make a match with a model partner switch the subject matter colloidal system class XI IPA MAN 1 Bengkulu City in the academic year 2017/2018. The research population of all classes XI IPA amounted to 4 classes with a total population of 151 students. The sampling of the research was done by normality test and homogeneity test before the study population. Obtained a sample of research that consists of 2 classes of class XI IPA 1 as an experimental class I that apply the model make a match and class XI IPA 2 as an experimental class II using a model parten switch. Student learning outcomes are seen from the postest score. Students' learning outcomes in the make a match class had an average of 82.714 while in the partner switch the average pair was 77.5. This shows that the model of make a match is more effectively used in the process of learning in class than the model of partner switch. From the t test-t test on both experiment classes is obtained tcount and ttable $=1.707>1.666(\alpha=0,05)$. The results show that H0 is rejected and Ha is accepted which means that there is a significant difference between the learning result of the students using make a match model and the learning model partner switch on the material of the colloidal system.

Key words : make a match, partner switch, learning outcomes, coloid system

\begin{abstract}
Abstrak
Penelitian ini bertujuan untuk mengetahui perbedaan hasil belajar siswa yang menggunakan model pembelajaran mencari pasangan dengan menggunakan model pembelajaran bertukar pasangan pada materi pelajaran sistem koloid dikelas XI IPA MAN 1 Kota Bengkulu pada tahun ajaran 2017/2018. Populasi penelitian seluruh kelas XI IPA berjumlah 4 kelas dengan total jumlah populasi 151 siswa. Pengambilan sampel penelitian dilakukan dengan uji normalitas dan uji homogenitas terlebih dahulu terhadap populasi penelitian. Didapat lah sampel penelitian yang terdri dari 2 kelas yaitu kelas XI IPA 1 sebagai kelas eksperimen I yang menerapkan model pembelajaran mencari pasangan dan kelas XI IPA 2 sebagai kelas eksperimen II yang menggunakan model pembelajaran bertukar pasangan. Hasil belajar siswa dilihat dari nilai postest. Hasil belajar siswa pada kelas mencari pasangan memiliki rata-rata sebesar 82,714 sedangkan pada kelas bertukar pasangan rata-rata sebesar 77,5. Hal tersebut menunjukkan bahwa model pembelajaran mencari pasangan (make a match) lebih efektif digunakan dalam proses pembelajaran dikelas dibanding model pembelajaran bertukar pasangan (partner switch). Dari hasl uji-t pada kedua kelas eksperimen didapat thitung dan ttabel $=1,707>1,666(\alpha=0,05)$. Hasil perhitungan menunjukkan H0 ditolak dan Ha diterima yang berarti bahwa adanya perbedaan yang signifikan antara hasil belajar siswa yang menggunakan model pembelajaran mencari pasangan dan model pembelajaran bertukar pasangan pada materi sistem koloid.
\end{abstract}

Kata kunci : Mencari pasangan, Bertukar pasangan, Hasil belajar, Sistem koloid.

\section{PENDAHULUAN}

Pendidikan merupakan hal yang sangat penting yang tidak dapat dipisahkan dari kehidupan manusia, berbagai upaya pun dilakukan manusia untuk mendapatkan pendidikan [1]. Sepanjang waktu dunia pendidikan dituntut untuk lebih meningkatkan kualitasnya [2].

Untuk meningkatkan kualitas pendidikan di sekolah dapat dilakukan antara lain berupa perbaikan pada proses pembelajaran [3] yang ditandai dengan terjadinya interaksi atau hubungan timbal balik antara guru dengan siswa [4].

Dalam proses pembelajaran, guru dan siswa merupakan dua komponen yang tidak bisa dipisahkan [5] , dimana dua komponen tersebut harus menjalin interaksi yang saling menunjang agar hasil belajar siswa dapat tercapai secara optimal [6].

Untuk memperoleh hasil belajar yang 
optimal perlu didukung dengan pemilihan metode yang sesuai serta alat penilaian yang dapat mengukur keberhasilan dari proses belajar mengajar [7].

Salah satu wujud perilaku guru yang dapat dilakukan untuk mencapai tujuan pembelajaran adalah penggunaan variasi model pembelajaran [8].

Model pembelajaran menunjukkan suatu pendekatan pembelajaran tertentu yang meliputi tujuan, sintak, lingkungan, dan sistem pengolahannya [9], yang berfungsi sebagai sarana komunikasi yang penting [10].

Penggunaan model pembelajaran tertentu memungkinkan guru dapat mencapai tujuan pembelajaran tertentu dan bukan tujuan pembelajaran yang lain [11].

Model pembelajaran yang diterapkan harus disesuaikan dengan mata pelajaran dan materi yang akan diajarkan [12]. Salah satu mata pelajaran yang kurang digemari oleh siswa yaitu mata pelajaran kimia [13].

Dari hasil pengamatan langsung dikelas XI IPA MAN 1 Kota Bengkulu pada tahun ajaran 2017/2018 pada saat proses pembelajaran kimia dikelas, terlihat bahwa masih ada siswa yang kurang tertarik dan berpartisipasi aktif dalam mengikuti proses pembelajaran, bahkan ada siswa yang berperan pasif tanpa memberi respon apa pun selama proses pembelajaran berlangsung, yang menyimpulkan bahwa terjadi penurunan minat belajar pada siswa [14].

Untuk membangkitkan minat dan motivasi siswa maka perlu dilakukannya perubahan pada pola pengajaran didalam kelas[15], yang biasanya dengan menciptakan suasana yang nyaman dan menyenangkan didalam kelas [16].

Salah satu upaya didalam meningkatkan minat belajar siswa yaitu dengan menerapkan model pembelajaran kooperatif [17].

Dalam model pembelajaran kooperatif siswa akan belajar dalam kelompok kecil untuk mencapai satu tujuan [18]. Ada beberapa model pembelajaran kooperatif yang dianjurkan pada kurikulum 2013 antara lain model pembelajaran make a match (MM) dan model pembelajaran partner switch (PS).

Ciri khas dari model pembelajaran MM adalah berupaya siswa make a match dari kartu yang merupakan jawaban dari soal dalam waktu tertentu [19], sedangkan untuk model pembelajaran PS siswa membentuk kelompok kecil/ berpasangan untuk menyelesaikan permasalahan kemudian partner switch untuk mendiskusikan permasalahan yang sama sehingga diharapkan dapat memperoleh jawaban yang lebih akurat, hasil diskusi terhadap pasangan lain kemudian dibagikan kepada pasangan semula [20].

Kedua model tersebut termasuk model pembelajaran aktif dan dapat membuat suasana kelas menjadi menyenangkan karena terdapat unsur permainan pada proses pembelajaran[21].

Bermain dan belajar memiliki persamaan yaitu keduanya terjadi perubahan, yaitu dapat mengubah tingkah laku, sikap dan pengalaman [22]. Perubahan tingkah laku dan sikap yang positif dapat berpengaruh dalam proses meningkatkan motivasi yang dimiliki siswa [23].

Pembelajaran akan menjadi efektif dan bermakna apabila siswa termotivasi untuk belajar sehingga tujuan dalam proses pembelajaran dapat tercapai dengan baik serta dapat meningkatkan hasil belajar siswa [24].

Dalam memilih model mana yang lebih tepat diterapkan pada proses pembelajaran dikelas bukan sesuatu yang mudah, selain itu kedua model ini juga memiliki banyak kesamaan dalam penerapan dan pelaksanaannya.

Berdasarkan hal tersebut peneliti tertarik meneliti dengan membandingkan hasil belajar siswa yang menggunakan model pembelajaran make a match dan hasil belajar siswa menggunakan model pembelajaran partner switch.

\section{METODE PENELITIAN}

Jenis penelitian ini adalah penelitian eksperimen semu (quasi eksperimental), yang dilakukan dengan pengontrol sesuai dengan situasi yang ada [25].

Penelitian ini dilakukan pada dua kelas yaitu kelas kelas Eksperimen I dan Kelas Eksperimen II, dimana kelas tersebut diberi perlakuan yang berbeda dalam model pembelajarannya.

Populasi pada penelitian ini adalah seluruh siswa kelas XI IPA MAN 1 Kota Bengkulu tahun ajaran 2017/2018 yang berjumlah 4 kelas.

Sampel penelitian diperoleh setelah melakukan uji normalitas dan homogenitas terlebih dahulu terhadap populasi penelitian. [26].

Instrumen penelitian yang digunakan yaitu test berupa posttest untuk mengetahui hasil belajar siswa tiap kelas eksperimen yang menerapkan 
model pembelajaran yang berbeda [27].

Hasil dari posttest dianalisis dengan mencari nilai rata - rata postest siswa, kemudian uji normalitas menggunakan KolmogorovSmirnov dan Shapiro-Wilk pada program SPSS Versi 16.00 , uji homogenitas menggunakan uji $\mathrm{F}$ dan yang terakhir uji hipotesis menggunakan uji $\mathrm{T}$.

\section{HASIL DAN PEMBAHASAN}

Berdasarkan hasil observasi awal terlihat bahwa sebelum diterapkannya model pembelajaran, minat belajar siswa mengalami penurunan sehingga membuat hasil belajar siswa menjadi rendah.

Berdasarkan nilai UAS kimia semester ganjil kelas XI IPA diperoleh data uji normalitas sebagai berikut (Tabel 1) :

Tabel 1. Hasil Uji Normalitas Populasi

\begin{tabular}{|c|r|r|r|r|l|}
\hline \multirow{2}{*}{$\begin{array}{l}\text { Nilai } \\
\text { UAS } \\
\text { Kela }\end{array}$} & \multicolumn{5}{|c|}{ Kolmogorov-Smirnov } \\
\cline { 2 - 6 } & Stat. & Df & \multicolumn{1}{|c|}{ T hitung. } & T tabel & Hasil \\
\hline IPA 1 & 0.120 & 0.36 & $0.200^{*}$ & 0,05 & Normal \\
\hline IPA 2 & 0.110 & 0.38 & $0.200^{*}$ & 0,05 & Normal \\
\hline IPA3 & 0.120 & 0.39 & 0.167 & 0,05 & Normal \\
\hline IPA 4 & 0.116 & 0.39 & $0.200^{*}$ & 0,05 & Normal \\
\hline & \multicolumn{5}{|c|}{ Shapiro-Wilk } \\
\hline IPA 1 & 0.962 & 0.36 & 0.254 & 0,05 & Normal \\
\hline IPA 2 & 0.968 & 0.38 & 0.330 & 0,05 & Normal \\
\hline IPA3 & 0.961 & 0.39 & 0.192 & 0,05 & Normal \\
\hline IPA 4 & 0.965 & 0.39 & 0.258 & 0,05 & Normal \\
\hline
\end{tabular}

Kriteria normal diperoleh yaitu jika nilai T-hitung $>\mathrm{T}$ tabel $=0,05$ dan dari tabel 1 diatas diperoleh bahwa pada ke 4 kelas

populasiyang diuji terbukti

m e miliki distribusi normal sehingga dapat dilanjutkan untuk uji homogenitas sampel.

Untuk hasil uji homogenitas menggunakan uji F, diperoleh data sebagai berikut (Tabel 2).

Tabel 2. Hasil Uji Homogenitas Populasi

\begin{tabular}{|l|l|}
\hline Kelas & Hasil Penelitian \\
\hline$F_{\text {Hitung }}$ & 1,242 \\
\hline$F_{\text {Tabel }}$ & 2,73 \\
\hline
\end{tabular}

Kriteria homogen jika $F_{\text {hitung }}<\mathrm{F}_{\text {tabel }}$, dan dari data penelitian di peroleh bahwa Fhitung = 1,242 < FTabel $=2,73$ maka semua kelas adalah dinyatakan homogen.

Untuk kelas penelitian (sampel) digunakan 2 kelas yaitu kelas XI IPA 1 berjumlah 35 siswa sebagai kelas eksperimen I yang menerapkan model pembelajaran make a match (MM) dan kelas XI IPA 2 berjumlah 38 siswa sebagai kelas eksperimen II yang menerapkan model pembelajaran partner switch (PS).

Penerapn kedua model pembelajaran pada kedua kelas eksperimen diharapkan mampu untuk menarik minat belajar siswa sehingga dapat eningkatkan hasil belajar siswa.

Pelaksanaan proses pembelajaran dilakukan dalam dua kali pertemuan, dan setelah proses pembelajaran selesai dilanjutkan dengan postest untuk melihat keberhasilan pengajaran dan mengetahui apakah siswa memahami materi yang telah diberikan.

Berdasarkan hasil perhitungan yang diperoleh (Gambar 1), nilai rata-rata untuk kelas eksperimen I sebesar 82,714 sedangkan untuk nilai rata-rata postes kelas eksperimen II sebesar 77,5 , yang menunjukkan adanya perbedaan hasil belajar antar kelas eksperimen.

Data hasil belajar yang diambil dari nilai rata-rata postes dapat disajikan dalam grafik berikut (Gambar 1)

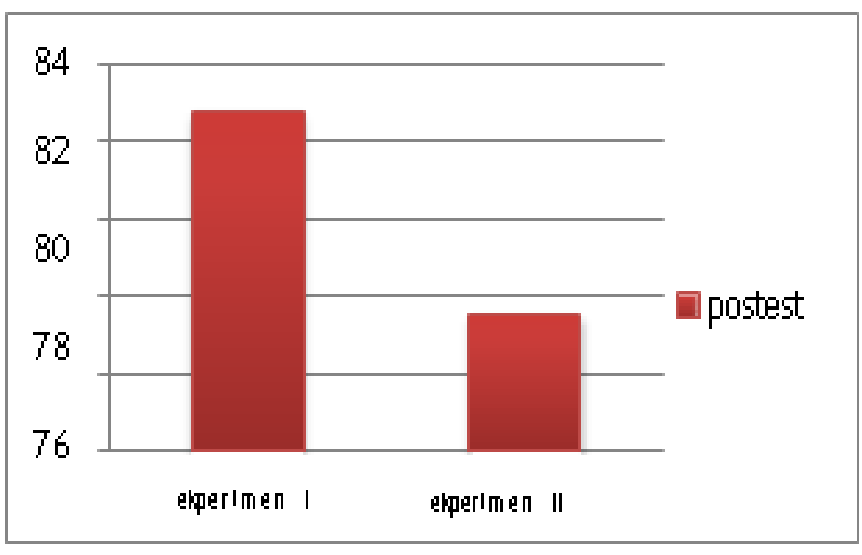

Gambar .1 Grafik hasil belajar siswa

Hasil belajar sebagai perubahan sikap atau tingkah laku setelah anak melakukan kegiatan belajar [28], yang merupakan suatu akibat dari proses belajar yang dapat diukur dengan menggunakan alat pengukuran yaitu berupa tes yang disusun secara terencana baik tes tulis, tes 
lisan maupun tes perbuatan [29].

Karena itu dapat disimpulkan hasil belajar merupakan sebagai tingkat keberhasilan siswa dalam mempelajari materi pelajaran di sekolah yang dinyatakan dalam skor yang diperoleh dari hasil tes mengenal sejumlah materi pelajaran tertentu [30].

\section{Hasil belajar siswa yang} menggunakan model pembelajar MM pada kelas eksperimen I lebih tinggi dibandingkan kelas ekperimen II yang menggunakan model pembelajaran PS yang menunjukkan bahwa proses pembelajaran dengan menerapkan model pembelajaran MM lebih baik dan efektif serta dapat meningkatkan hasil belajar siswa dibandingkan pembelajaran yang menerapkan model pembelajaran PS .

Hasil uji normalitas, homogenitas dari hasil belajar pada kedua kelas dapat dilihat pada tabel 3 dan tabel 4.

Tabel 3. Hasil uji normalitas kelas sampel

\begin{tabular}{|l|r|r|r|r|r|r|}
\hline \multirow{2}{*}{$\begin{array}{l}\text { Nilai } \\
\text { UAS } \\
\text { Kelas }\end{array}$} & \multicolumn{3}{|c|}{ Kolmogorov- } & \multicolumn{3}{c|}{ Shapiro-Wilk } \\
\cline { 2 - 7 } & Stat. & Df & Sig. & \multicolumn{1}{c|}{ Stat. } & \multicolumn{1}{c|}{ Df } & Sig. \\
\hline IPA 1 & .140 & 35 & .081 & .939 & 35 & .052 \\
\hline IPA 2 & .138 & 38 & .064 & .946 & 38 & .068 \\
\hline
\end{tabular}

Tabel 4. Hasil uji homogenitas Dan Hipotesis kelas sampel

\begin{tabular}{|l|l|l|}
\hline No & \multicolumn{1}{|c|}{ Data } & \multicolumn{1}{c|}{ Hasil Perhitungan } \\
\hline 1 & F $_{\text {Hitung }}$ & 2,198 \\
\hline & thitung & 1,707 \\
\hline 2 & F $_{\text {Tabel }}$ & 3,98 \\
\hline & ttabel & 1,666 \\
\hline
\end{tabular}

Berdasarkan perhitungan uji normalitas, data hasil belajar siswa pada kedua kelas eksperimen dinyatakan berdistribusi normal dengan nilai signifikansi > 0,05 (Tabel 3) dan hasil uji homogenitas (Tabel 4) diperoleh bahwa $\mathrm{F}_{\text {hitung }}=2,198<\mathrm{F}_{\text {tabel }}=3,98$ yang menunjukkan bahwa kedua kelas eksperimen memiliki varians yang homogen.

Hasil uji hipotesis menggunakan uji t, diperoleh data bahwa Nilai $\mathrm{t}_{\text {hitung }}=1,707>$

$\mathrm{t}$ tabel $=1,666$ yang menandakan bahwa $\mathrm{Ha}$ diterima sedangkan $\mathrm{H} 0$ ditolak yang berarti bahwa terdapat perbedaan yang signifikan antara hasil belajar siswa yang menggunakan model pembelajaran MM dengan yang menggunakan model pembelajaran PS dalam kelompok diskusi.

Dalam pelaksanaan model pembelajaran PS menuntut siswa untuk memecahkan masalahnya secara mandiri dengan berdiskusi antar anggota, yang walaupun dikerjakan secara berkelompok ternyata masih ditemui siswa yang tidak ikut serta mengerjakan tugas. Hal ini dapat diatasi dengan mengadakan pertukaran antar anggota kemompok dimana setiap anggota kelompok diberi tugas untuk menjelaskan hasil diskusinya kepada kelompok lain dan kemudian saling bertukar pendapat sehingga setiap anggota kelompok diharuskan memahami dan menguasai hasil diskusi yang telah mereka kerjakan. Sedangkan model pembelajaran MM siswa, dihadapkan pada suatu masalah atau soal dimana jawaban dari soal yang diberikan sudah disediakan oleh guru, sehingga tugas siswa hanya mencocokkan antara soal dan jawaban yang telah diberikan.

Model pembelajaran MM menuntut guru untuk dapat menyediakan soal dan jawaban yang bervariasi sehingga dapat membuat siswa lebih berpikir kritis, sehingga materi yang disampaikan dapat mereka pahami secara utuh [31].

Kedua model pembelajaran kooperatif tersebut terbukti dapat membantu siswa dalam memahami materi pelajaran yang diberikan oleh guru. Dari model yang digunakan pada proses pembelajaran ada perbedaan dari masing-masing model sehingga peningkatan hasil belajar siswa juga berbeda.

Hal tersebut juga tidak terlepas dari peran dan pengawasan seorang guru selama proses pembelajaran berlangsung [32]. Guru juga harus bisa mengendalikan jalannya pembelajaran dan memanfaatkan waktu yang disediakan dengan baik, karena jika tidak maka proses pembelajaran tidak akan berjalan maksimal dan sesuai dengan yang diharapkan [33].

\section{KESIMPULAN}

Berdasarkan hasil penelitian menunjukkan bahwa peningkatan hasil belajar siswa lebih tinggi menggunakan model pembelajaran make a match dibanding model pembelajaran partner switch.

Terdapat perbedaan yang signifikan antara hasil belajar siswa yang menggunakan model pembelajaran make a match dengan yang 
menggunakan model pembelajaran partner switch.

Hal ini terlihat dari hasil uji t dan didapat nilai thitung yaitu 1,707 lebih besar dari tabel yaitu 1,666.

\section{SARAN}

Pada model pembelajaran make a match hendaknya guru menempatkan posisi kelompok secara berurutan sesuai nomor kelompok masingmasing. Sedangkan pada model pembelajaran partner switch guru harus terus memandu siswa dalam melakukan diskusi kelompok agar tidak keluar dari topik bahasan tugas yang diberikan kelompok, tapi terkadang hasil yang didapat kurang tepat atau sedikit keluar dari topik pembahasan yang diberika. Sehingga disini perlu adanya pengawasaan dari guru untuk menuntun jalannya diskusi agar berjalan dengan baik.

\section{DAFTAR PUSTAKA}

[1] Muhardi, Kontribusi Pendidikan Dalam

Meningkatkan Kualitas Bangsa

Indonesia, Mimbar, 2004: 20(4): 478-

492.

[2] Muhson, A., Meningkatkan

Profesionalisme Guru: Sebuah Harapan,

Jurnal Ekonomi \& Pendidikan, 2004: 2

(1): 90-98.

[3] Medianty, S.U., Amrul Bahar,

Elvinawati , Penerapan Model

Discovery Learning Dengan

Menggunakan Media Video Untuk

Meningkatkan Aktivitas Belajar Dan

Hasil Belajar Siswa Kelas XI IPA 1

SMAN 1 Kota Bengkulu, Alotrop, 2018:

2(1): 58-65

[4] Suhandi, A., Strategi Guru Dalam Menumbuhkan Minat Belajar Sains Di

Sekolah Dasar, Gentala Pendidikan Dasar, 2017: 2(2): 1-17.

[5] Hanafy, M.S., Konsep Belajar Dan Pembelajaran, Lentera Pendidikan, 2014: 17(1): 66-79.

[6] Rozikin, S., Hermansyah Amir, Salastri Rohiat, Hubungan Minat Belajar Siswa Dengan Prestasi Belajar Siswa Pada Mata Pelajaran Kimia Di SMA Negeri 1 Tebat Karai Dan SMA Negeri 1 Kabupaten Kepahiang,Alotrop, 2018: 2(1): 78-81.

[7] Simanjuntak , N,D,P, Salastri Rohiat,
Elvinawati, Hubungan Antara Sarana Laboratorium Terhadap Ketrampilan Proses Sains Siswa Kelas XI MIPA 5 Di SMA Negeri 3 Kota Bengkulu, Alotrop .2017: 1(2): 102-105.

[8] Lestari, I.A, Hermansyah Amir, Salastri Rohiat Hubungan Persepsi Siswa Kelas $X$ MIPA Di SMA Negeri Sekota Bengkulu Tahun Ajaran 2016/2017 Tentang Variasi Gaya Mengajar Guru Dengan Hasil Belajar Kimia, Alotrop, 2017:1(2): 113-116.

[9] Gusti, N, Amrul Bahar, Dewi Handayani .Studi Perbandingan Pembelajaran Kooperatif Menggunakan Media Chemical Domino Card Dan Flash Card , Alotrop .2017: 1(2): 85-88.

[10] Ginting, S.M., Hermansyah Amir., Penerapan Model Pembelajaran Somatis, Auditori, Visual danIntelektual (SAVI) Berbantuan Media Komputer Untuk Meningkatkan Kualitas Pembelajaran Kimia Fisik II, Exacta,2012:10(1): 98105

[11] Wahyuni., N.D, Amrul Bahar, Dewi Handayani, Perbandingan Hasil Belajar Kimia Model Pembelajaran Problem Based Learning Dan Think Talk Write , Alotrop , 2017: 1(2) : 144-147

[12] Sari, Y.A, Amrul Bahar, Salastri Rohiat., Studi Perbandingan Pembelajaran Kooperatif Menggunakan Media Kartu Pintar Dan Kartu KemudiPintar, Alotrop .2017: 1(1): 44-48

[13] Viani, D.S, Amrul Bahar, dan Elvinawati. Perbandingan Hasil Belajar Siswa Menggunakan Media Chemopoly Game Dan Tournament Question Card. Alotrop . 2017: 1(1): 55-59

[14] Nurhasanah, S., A. Sobandi., Minat Belajar Sebagai Determinan Hasil Belajar Siswa, Jurnal Pendidikan Manajemen Perkantoran, 2016: 1(1): 128-135

[15] Rahmayanti, V., Pengaruh Minat Belajar Siswa Dan Persepsi Atas Upaya Guru Dalam Memotivasi Belajar Siswa Terhadap Prestasi Belajar Bahasa Indonesia Siswa SMP Di Depok, Jurnal SAP , 2016: 1 (2): 206-216.

[16] Elvinawati., Sumpono., Hermansyah Amir., Lessons Study Pada Mata Kuliah 
Kimia Sekolah I Sebagai Upaya Peningkatan Kualitas Pembelajaran Dan Pembangunan Karakter (Character Building), Exacta, 2012: 10(2): 156-159.

[17] Wiwit., Hermansyah.Amir, Dody Dori Putra, Penerapan Model Pembelajaran Kooperatif Tipe TGT dengan dan Tanpa Media Penggunaan Media Animasi Terhadap Hasil Belajar Kimia Siswa SMA Negeri 9 Kota Bengkulu. Exacta, 2012: 10 (1) : 71-78

[18] Rosita, I., Leonard., Meningkatkan Kerja Sama Siswa Melalui Pembelajaran Kooperatif Tipe Think Pair Share, Jurnal Formatif , 2015: 3(1): 1-10.

[19] Lestina, M., H. Mashudi, Okianna Penerapan Model Pembelajaran Kooperatif Tipe Make A Match Untuk Meningkatkan Motivasi, Jurnal Pendidikan dan Pembelajaran Khatulistiwa, 2014: 3 (3) : 1-10.

[20] Marsantika , Muhammad Zulfajri., Efektivitas Peningkatan Pemahaman Siswa Terhadap Materi Sistem Koloid dengan Menggunakan Model Pembelajaran Partner Switch, J.Edu. Kim, 2017 : 2(1), 72-78

[21] Syofiana,N., Salastri Rohiat, Hermansyah Amir.,Perbandingan Hasil Belajar Siswa Menggunakan Model Pembelajaran Kooperatif Tipe Make A Match (MM) Dan Team Games Tournament (TGT) Pada Mata Pelajaran Kimia Di Kelas X IPA MAN 1 Kota Bengkulu, Alotrop, 2018 : 2(2): 122-131.

[22] Zalyana., Perbandingan Konsep Belajar, Strategi Pembelajaran dan Peran Guru (Perspektif Behaviorisme dan Konstruktivisme), Jurnal Al-hikmah , 2016: 13(1): 71-81.

[23] Amir,H., Korelasi Pengaruh Faktor Efikasi Diri Dan Manajemen Diri Terhadap Motivasi Berprestasi Pada Mahasiswa Pendidikan Kimia Universitas Bengkulu, Manajer Pendidikan, 2016: 10(4): 336-342.

[24] Masdiyo, Upaya Meningkatkan Motivasi Dan Hasil Belajar Lompat Jauh Gaya Jongkok Dengan Penerapan Model Pembelajaran Kooperatif STAD Pada Siswa Kelas SDN Batokerbuy 5 Kabupaten Pamekasan Tahun Pelajaran
2015/2016, Jurnal Sportif, 2016: 2 (1): 59-64.

[25] Novela, M, Amrul Bahar, Hermansyah Amir , Perbandingan Hasil Belajar Siswa Dengan Metode Index Card Match Dan Bamboo Dancing, Alotrop , 2017: 1(2) : 123-126.

[26] Meilan, W., Salastri Rohiat,Hermansyah Amir. Perbandingan Hasil Belajar Siswa Menggunakan Media Call Card Dan Truth And Dare, Alotrop. 2017: 1(1): 39-43.

[27] Saputri,R.J., Sumpono,Rina Elvia., Perbandingan Hasil Dan Minat Belajar Kimia Siswa Kelas X IPA Menggunakan Model Pembelajaran Kooperatif Snowball Throwing Dan Talking Stick Pada Kurikulum 2013 Di SMAN 10 Kota Bengkulu, Alotrop, 2018: 2(2): 166-174.

[28] Mutaqwiyati,I.,Nurhamidah,

Hermansyah Amir, Penerapan Model Pembelajaran Problem Based Instruction (PBI) Dengan Menggunakan Media Audio -visual Untuk Meningkatkan Aktivitas Belajar Dan Hasil Belajar Siswa Di SMA N 09 Kota Bengkulu , Alotrop, 2018: 2(2): 184-190.

[29] Sudijono, Anas. 2011. Pengantar evaluasi pendidikan. Jakarta: PT. Raja Grafindo. ISBN : 979-421-495-7

[30] Ricardo, Rini Intansari Meilani., Impak minat dan motivasi belajar terhadap hasil belajar siswa, Jurnal Pendidikan Manajemen Perkantoran, 2017: 1(1): 7992

[31] Yunita, A., Salastri Rohiat, Hermansyah Amir , Analisis Kemampuan Berpikir Kritis Mata Pelajaran Kimia Pada Siswa Kelas XI IPA SMAN 1 Kepahiang, Alotrop, 2018: 2(1): 33-38

[32] Ismail, M.I., Kinerja Dan Kompetensi Guru Dalam Pembelajaran , Lentera, 2010: 13(1): 44-63.

[33] Faruqi, D., Upaya Meningkatkan Kemampuan Belajar Siswa Melalui Pengelolaan Kelas, Evaluasi, 2018: 2(1): ,294-310.

Penulisan Sitasi Artikel Ini Adalah Aprianika,S., Amrul Bahar, Salastri Rohiat., Penerapan Model Pembelajaran Mencari Pasangan Dan Bertukar Pasangan Dalam Kelompok Diskusi 
Terhadap Hasil Belajar Siswa Pada Materi Sistem

Koloid Kelas XI IPA MAN 1 Kota Bengkulu , Alotrop, 2019: 3(1): 98-104. 